\title{
Smart Retail, Replaces All? Some? : Different Influence of Amazon Go to Local Restaurant Industry.
}

\author{
JooYoung Choi \\ Business and Technology \\ Management, Korea \\ Advanced Institute of \\ Science and Technology \\ jooyoungchoi@kaist.ac.kr
}

\author{
Chul Ho Lee \\ Business and Technology \\ Management, Korea \\ Advanced Institute of \\ Science and Technology \\ irontigerlee@kaist.ac.kr
}

\author{
Yasin Ceran \\ Business and Technology \\ Management, Korea \\ Advanced Institute of \\ Science and Technology \\ yceran@kaist.ac.kr
}

\author{
Sunghun Chung \\ Leavey School of \\ Business, Santa Clara \\ University \\ shchung@scu.edu
}

\begin{abstract}
Amazon Go, the pioneering smart retailer, has been opening physical stores in metropolitan areas of the USA, and seductively distracted customers from adjacent competitors by provisioning quick-and-easy service. This study focuses on how the appearance of the smart retailer affects adjacent competing businesses. We constructed a panel dataset with various features and reviews of restaurants from Yelp.com, and created two dummies, Adjacent, one if the restaurant is in a certain radius of a smart retailer and zero outside, and After, one after the introduction and zero before. By using Difference-in-Difference estimation, we find that (1) negative impacts on the adjacent restaurants after Amazon Go compared to non-adjacent and before the appearance, and (2) less negative impact on adjacent fine-dining restaurants than fast-food restaurants. After Amazon Go, customers' sentiments about the adjacent restaurants have changed more negatively. This paper may provide businesses with useful implications for their strategies.
\end{abstract}

Keywords: Smart Retail, Yelp, Substitute, Complement, Difference in Difference (DID).

\section{Introduction}

Do you believe technical innovation makes a difference in choosing your meal? Imagine a central district that has lots of offices like Manhattan. How about if some incredibly convenient store that can shorten your time to buy lunch comes in the middle of this area? Is the state-of-art store a crisis of local restaurants and food stores? Is it a hero of them by letting more people flourish in the area? This study analyzes how technically innovative competitors disrupt other market participants differently by the example of Amazon Go. Because going Amazon Go is a good alternative to going to restaurants for office workers, the entry of Amazon Go can be a proper proxy for the "external shock" for consumer behavior and enables estimation by difference-in-differences.

\section{Literature review}

\subsection{Need of paying attention to smart retail.}

From the perspectives of consumers, the experience of using brick-and-mortar stores has been improved dynamically. They have adopted convenient technology fast. The number of proximity mobile payment users in the US is estimated as 71.5 million in 2019, and it increased to 92.3 million after the pandemic in 2020 . The volume of transactions through mobile wallets is also increasing. About $\$ 182$ billion transacted in-store via mobile wallets in the US, more than $\$ 30$ billion from the prior estimation. According to the survey investigating 1,055 US internet users in $2020,43 \%$ of them tried curbside pickup of digital order, $27 \%$ of them tried in-store pickup of digital order, and $13 \%$ of them used a mobile phone to pay in-store as a first-time shopping behavior after pandemic [1]. Such a trend shows the growing familiarity of consumers' new types of payment and accelerated adoption of new technology using stores after a pandemic. This change can be a challenge to conventional retail or restaurants. If a category undergoes a revolution to the experience of the consumers, they get used to the convenience. For example, people can feel burdensome for traditional experiences, calling a taxi or exchanging money, after using Uber [2].

This stream is also clear on the perspectives of retailers' sides. Jamie lannone, the CEO of Sam's Club's e-commerce, said one of the top issues when people shop in retail is with checkout. Figure 1 reveals 
that many customers are already familiar with shopping with mobile phones, and retail executives have been considering a cashless store to follow such a stream. Additionally, the dissatisfaction about waiting in the long line seems to be the pressure for a more convenient and faster alternative for their business.

(\% of respondents, $n=451$ )

We see an increase in customers using their mobile phones

for shopping in-store (e.g. coupons, payments, product information) $45 \%$

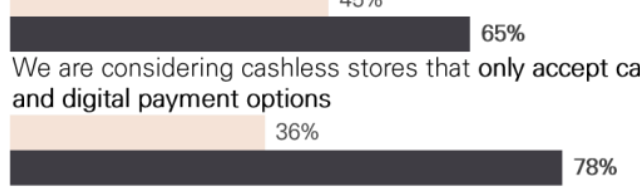

Customers sometimes complain about waiting too long in lines $53 \%$

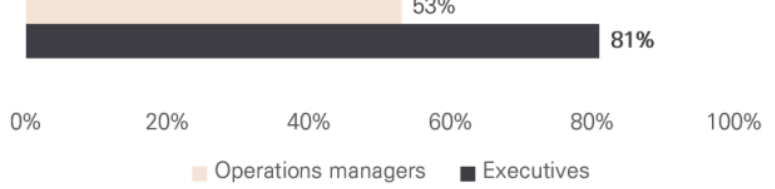

Figure 1. Survey of US B2C retail executives

Enhancing the understanding impact of smart retail is required to catch the trend of the US retail market. Amazon Go is the pioneer of smart retail. They conceptualized, designed the structure of the new kind of retail store. They satisfied the inevitable needs of a customer who wants a convenient payment experience and does not want a long waiting line. They have opened and well-developed their portion in the market. They opened 26 stores in four cities by 2021. 7-Eleven, a powerful traditional player in the convenience store industry, also started to manage a pilot version of its cashier-less market in Texas in 2020. By observing the dynamics of challenges that Amazon Go made, we can get insight into the new trend of retail and local restaurants.

\subsection{Amazon Go as a tech shock to the local industry.}

Amazon Go is a grocery store that offers ready-toeat breakfast, lunch, and snack options. Amazon Go has provided its innovative services by using technologies to enable more convenient processes when we shop. Amazon Go lets people enter by just scanning their barcode of the Amazon Go app. If people take some product or food, the store automatically detects it and adds it to the virtual cart of each person. They realized this highly convenient store by deep learning algorithms, computer vision, and sensor fusion technology used in self-driving cars. They even let people walk out without waiting in line. Their purchase is complete when they walk out with a receipt in their app. An entryway like the subway turnstiles enabled this [3]. This surprising store has launched twenty-six branches in the US already.

Amazon Go is in four cities, Chicago, New York, San Francisco, and Seattle. All four cities are one of the main cities in the US that have lots of populations and offices. Especially in these cities, Amazon Go's attractive convenience can make people select Amazon Go rather than general small restaurants. Food from Amazon Go is a good alternative for many office workers who do not have enough time to enjoy their lunch.

Although Amazon Go opened in 2018 (the prototype version for employees launched in 2016), its impact on the neighborhood was discussed little. Blake et al. described the concept and utilized technologies of Amazon Go. They also suggested interesting discussion questions about competitors and the influence of Amazon Go [4]. Several studies conducted before or early after the opening of Amazon Go reported conflicting results about consumers' willingness. According to the survey of shorr, more than $25 \%$ of the respondents said they would pay more for grocery products if they don't need to wait in line at checkout [5]. However, another survey from YouGov stated that $66 \%$ of participants disagree that "I would be willing to pay more if it means avoiding checkout lines" [6]. Several tries are dealing with Amazon Go and its influence on the related market or consumer behavior. However, to the best of our knowledge, there is no empirical study on the effect of Amazon Go in local restaurants. Understanding the impact of Amazon Go on the restaurant industry is an important approach to enhance consumer behavior knowledge when they face the innovation of the buying experience. This approach is also valuable for retailers who must survive in the smart retail future.

By assuming the entry of Amazon Go as a technical shock in a specified area, we can expect different consumer behavior related to restaurant selection. Tech shock here means innovative customer experience driven by technology, distinguished from other competitors. The entry of Amazon Go is a treatment for this research.

\subsection{What restaurant will survive?}

Geography, user mobility, user rating, and review text are the key indicators to determine the long-term survival of a physical store [9]. The location and nearby places play a principal role in the popularity of the shop, and usually less competitiveness is the better. Specifically, more heterogeneity was an important 
issue. They proved it with data from Dianping.com known as "Yelp for China."

Location is dominant for the survival of restaurants [10]. There is a significant effect of location, as measured by U.S. postal zip codes, on restaurant failures. Additionally, restaurants that are smaller in size had higher failure rates than large-sized restaurants. They also proved that chain restaurants have significantly lower failure rates than independently owned restaurants.

There is a paper that proved the relationship of user rating and its impact on the restaurant [11]. In the paper, the author found that a one-star increase in Yelp rating leads to a 5-9 percent increase in revenue. The paper argues that online consumer reviews substitute for more traditional forms of reputation.

\subsection{The Goal for this paper}

We construct two main hypotheses based on the context above.

H1: The new competitor with innovative technology negatively influences a related market.

Hla: The treated reviews (restaurants near the Amazon Go, and reviews after the entry of Amazon Go) have a lower mean of star rating.

$H 1 b$ : The treated reviews (restaurants near the Amazon Go, and reviews after the entry of Amazon Go) have a lower mean of polarity score (sentiment score).

In this study, the new competitor is Amazon Go and the related market is the local restaurant industry that shares the food categories in Amazon Go. We can expect to see rebalances of restaurant layout near the Amazon Go and predict some kinds of gentrification. To estimate the customer behavior after using Amazon Go, we used star ratings and polarity score measured from restaurant reviews as perceived satisfaction of customers. If there is a negative impact, we will investigate further to find what features are the critical variables for making a difference in the degree of negative impact on each restaurant.

H2: Variation of perceived satisfaction of restaurants increased by Amazon Go.

This approach with two main hypotheses can show the effect of tech shock in a local business.

By dataset from Yelp, the most influential local business review platform, this study constructs a panel dataset with locations, the quality described by starrating, popularity measured by the number of reviews, and various characteristic features of each local restaurant. Many papers had used the data from Yelp, but it is the first time to scrutinize the impact of Amazon Go on local business by Yelp data.

Ultimately, this research implements Difference in differences (DID) estimation with a dependent variable, several performance indexes of local restaurants. In the last part of this paper, possible plans for these challenges are described.

This research contributes to the understanding of consumer behavior when there is a technical surprise in people's daily life. With this consumer comprehension, business owners or operators can get useful implications for their further strategies.

For the following part of this paper, the author justifies the nobility of data in this experiment. Then, the method and model of this experiment are specified. In the last, the results and the contribution of this work are discussed.

\section{Methods}

In this section, data used in this study and model specification are going to be provided. This experiment is for understanding the effect of Amazon Go's entry, which stands for the technical shock in the retail market, to the restaurant industry. Through the observation of the different trends of the treated group, which has been affected by Amazon Go, we can decompose how people change their behavior when they meet the surprisingly convenient alternative for their daily consumption.

\subsection{Data}

3.1.1. Why this research collected data from Yelp. This research obtains data from Yelp.com, the highly influential local business review platform in the US. Yelp accumulated more than 224 million reviews on their site by 2020 and $18 \%$ of them is about restaurants [12]. They provide not only reviews and ratings, but also detailed business information like price range, location, types of transaction, etc. Their user information is also valuable for a researcher who seeks data that can describe the character of consumers. Such nobility is mentioned in literature [13].

They compared the competitiveness of crowdsourced data from online platforms with data from Yelp. They showed that adding Yelp data can help marginally improve prediction performance compared to using only prior CBP (U.S. Customs and Border Protection) data. They also suggested that these new data sources, Yelp can be a useful complement to official government data. Though replacing the government data with crowdsourced data is still challenging but complementing it can allow for more timely and granular forecasts with a wider set of 
variables and a more complete view of the local economy. This result from this paper can be a crucial justification for using yelp data in my research (economically practical impact and more timely data). Many papers had used this valuable data however, it is the first time to scrutinize the impact of Amazon Go on local business by tons of Yelp data.

3.1.2. Process of collecting data. By 2021, Amazon Go has entered the four states in the US: New York, Washington, Illinois, and California. To get the restaurant's business information from the four states above, the author used "Yelp Fusion Business Search" which is the official API provided by Yelp.com. The term used for the API search was "restaurants", and locations were specified by zip code. The whole set of zip codes of the four states were from United States Zip Codes.org.

After collecting restaurant information, which is in the four states, the he "Yelp Fusion Business Details" API is used for gathering detailed data for each restaurant. Finally, 177,633 business data were collected. The results from Business Detail API were smaller than results from Business search API because the Detail API did not provide responses when there was no review in the business. Business information without review data is not suitable for this empirical setting, the author excluded them.

\begin{tabular}{|c|c|c|c|c|}
\hline State & $\begin{array}{c}\text { Search } \\
\text { API } \\
\end{array}$ & $\begin{array}{c}\text { Drop } \\
\text { Duplicate }\end{array}$ & $\begin{array}{c}\text { Location } \\
\text { Validation }\end{array}$ & $\begin{array}{c}\text { Detailed } \\
\text { API } \\
\end{array}$ \\
\hline NY & 571,904 & 73,500 & 47,168 & 47,021 \\
\hline $\mathrm{CA}$ & $1,128,643$ & 96,817 & 90,826 & 90,601 \\
\hline IL & 888,247 & 104,220 & 24,643 & 24,588 \\
\hline WA & 196,798 & 19,591 & 15,461 & 15,423 \\
\hline \multicolumn{4}{|c|}{ Sum } & 177,633 \\
\hline
\end{tabular}

Table 1. Number of business data collected from Yelp API.

Using the business information gathered from API, $8,021,122$ reviews and related reviewers' data (user info, rating of each review, and so on...) were collected with an original program made for this research.

Business information of each restaurant from API was combined with review data based on the restaurant ID. Then, panel data sets were constructed by reviewed dates or weeks.

\subsection{Model for empirical study}

To validate the H1: Amazon Go influences negatively to the local restaurant industry, the author labeled the treated group in the aspect of time and distance. Ultimately, this approach makes difference in the difference (DID) model to analyze the impact of certain events distinguished by both time and location. If a review was written after the entry of Amazon Go, the After ${ }_{t}$, dummy variable, was 1 . If the location of the restaurant of a review was within $150 \mathrm{~m}$ from Amazon Go, the Adjacent ${ }_{i}$, dummy variable, was 1. Therefore, we can understand the Treated $d_{i t}$ variable is denoted as follows:

Treated $_{i t}=$ After $_{t} *$ Adjacent $_{i}$.

Then, we can use the treated variable to test $\mathrm{H} 1$ in this model:

MeanofRating $_{i t}=B_{0}+B_{1}$ Treated $_{i t}+$

$B_{2}$ Higher $_{i}+B_{3}$ Overnight $_{i}+B_{4}$ Claimed $_{i}+$

$B_{5}$ Messaging $_{i}+B_{k} X_{i t}$.

MeanofPolarityScore $_{i t}=B_{0}+B_{1}$ Treated $_{i t}+$ $B_{2}$ Higher $_{i}+B_{3}$ Overnight $_{i}+B_{4}$ Claimed $_{i}+$ $B_{5}$ Messaging $_{i}+B_{k} X_{i t}$.

If we can find the results of the models (1-1) and (1-2) are significant and the $\mathrm{H} 1$ is true, we can step forwards to investigate what features are the critical variables for making a difference in the degree of negative impact on each restaurant. Rating is one of the strong characteristics of a restaurant which stands for general quality of services. The author made a dummy variable upto 2.5 star that describes whether a certain restaurant's reputation was bad or not. If the restaurant's representative star rating was same or below 2.5, upto 2.5 star was 1 . The Moderator $_{i t}$ variable is denoted as follows:

Moderator $_{i t}=$ After $_{t} *$ Adjacent $_{i} *$ upto2.5star $_{i}$.

This study substituted the Treated $d_{i t}$ variable with the Moderator $_{i t}$ variable in models (2-1) and (2-2):

MeanofRating $_{i t}=B_{0}+B_{1}$ Moderator $_{i t}+$
$B_{2}$ Higher $_{i}+B_{3}$ Overnight $_{i}+B_{4}$ Claimed $_{i}+$
$B_{5}$ Messaging $_{i}+B_{k} X_{i t}$.

MeanofPolarityScore $_{i t}=B_{0}+B_{1}$ Moderator $_{i t}+$ $B_{2}$ Higher $_{i}+B_{3}$ Overnight $_{i}+B_{4}$ Claimed $_{i}+$ $B_{5}$ Messaging $_{i}+B_{k} X_{i t}$.

\section{Empirical Analysis}

This research aims to prove the impact of Amazon Go's entry on local restaurants. In particular, this paper assumes that there is a different magnitude of effect on 


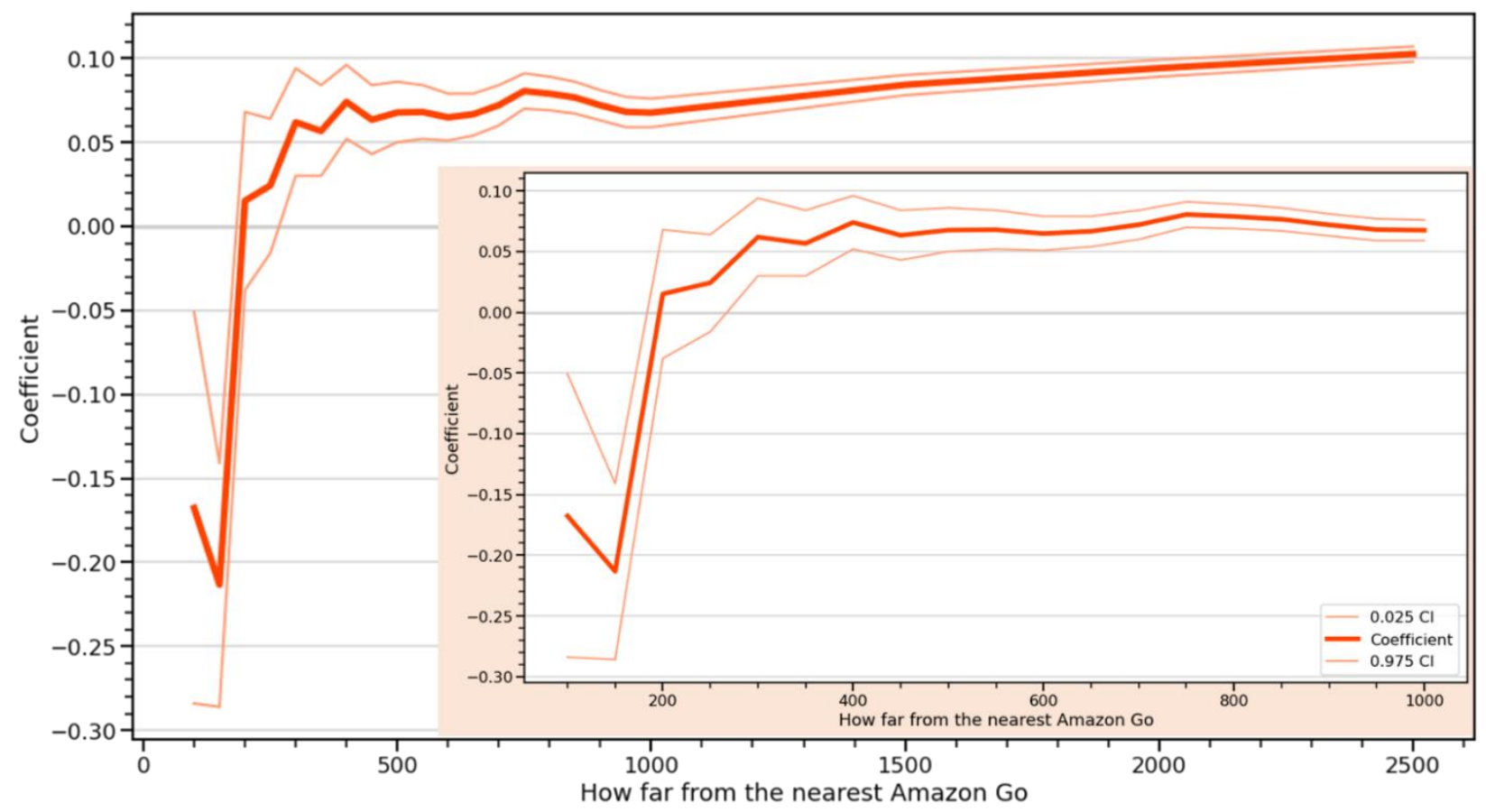

Figure 2. Coefficients are fluctuated by treated distance.

local restaurants whether the business has differentiated competitiveness.

The difference in Difference (DID) method enables this research to examine the influence of Amazon Go to the restaurants that we have interest only in. The treated group consists of reviews written after the entry of Amazon Go, and they are from the restaurants located near Amazon Go. In this section, the results and interpretation of them will be described.

\subsection{Selecting the point of treated distance Model for empirical study}

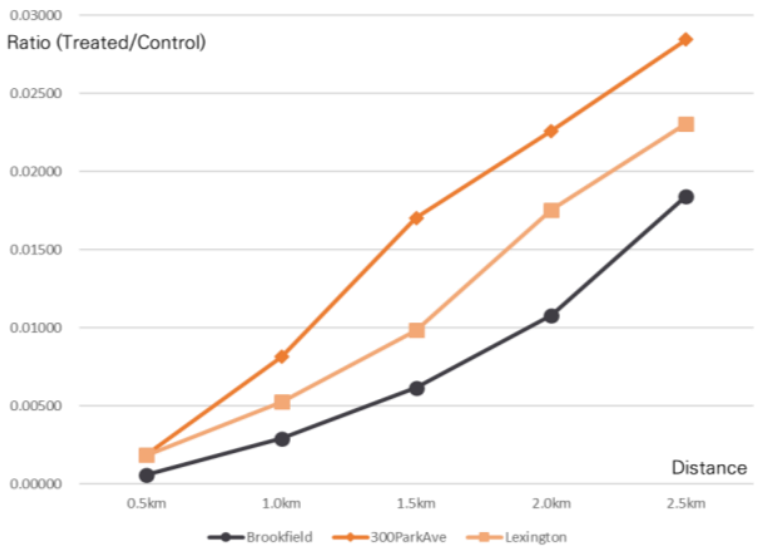

Figure 3. Observed treated group ratio decreases as the distance is shorter.
Before modeling the impact of Amazon Go, we had to select what standard would be used for the treated group. In this experiment setting, treated time is clear because it is determined by each entry date of the Amazon Go store. However, treated distance has to be set because there is no clear threshold up to what distance is close. To discuss the point of adjacent, the researcher estimated the coefficient of each treated group when the dependent variable is a mean rating of a restaurant. From the coefficient result of Amazon Go's effect on New York described in Figure 2, we can see few differences beyond the $1 \mathrm{~km}$. Figure 3 shows the observation ratio of the treated group versus the control group by distance. The shorter the distance, the lower the coefficient has come out. However, the number of treated groups is going to be too rare as the distance goes short. Therefore, this paper set the treated distance as $150 \mathrm{~m}$ from the Amazon Go considering the balance of treated group ratio and impact of Amazon Go.

\subsection{Results of DID Model}

In this study, the time dummy indicating the reviews were written after the entry of Amazon Go or not was multiplied by an adjacent dummy indicating that restaurants were located within $150 \mathrm{~m}$ from the closest Amazon Go to make DID settings. Table 2 shows that the OLS results of Amazon Go in New York support the hypothesis of this study. The direction of the estimated coefficient of the treated group is negative about all the dependent variables measuring the 
Table 2. Model Results of Amazon Go branches in New York.

\begin{tabular}{|c|c|c|}
\hline Model: & 1 & 2 \\
\hline Dependent variables & Mean ratings & Polarity Scor \\
\hline \multirow[t]{2}{*}{ (Scale) } & $(1 \sim 5)$ & (Sentiment S \\
\hline & & $(-1 \sim 1)$ \\
\hline (Intercept) & $3.5458 * * *$ & $0.5463 * * *$ \\
\hline \multicolumn{3}{|l|}{ Independent variables } \\
\hline After Amazon Go * Adjacent & $-0.2456 * * *$ & $-0.0628 * * *$ \\
\hline \multicolumn{3}{|l|}{ Control variable } \\
\hline After NY branch 1 (Brookfield) & $-0.0371 * * *$ & $-0.0168 * * *$ \\
\hline After NY branch 1 (300ParkAve) & -0.0033 & -0.0022 \\
\hline After NY branch 1 (Lexington) & $0.0216 * * *$ & $0.0101 * * *$ \\
\hline Relative Competitiveness & $0.5475 * * *$ & $0.1331 * * *$ \\
\hline Counts of open at overnight time & $-0.0433 * * *$ & $-0.0157 * * *$ \\
\hline Owner claimed the business & $0.1857 * * *$ & $0.0929 * * *$ \\
\hline Enabled messaging service & $0.0453 * * *$ & $0.0131 * * *$ \\
\hline
\end{tabular}

Year $2004 \sim 2021$ (without Year 2019 for multicollinearity)

\begin{tabular}{lcc}
\hline Adjusted $R^{2}$ & 0.031 & 0.017 \\
\hline F-statistic & $4597.0 * * *$ & $2537.0 * * *$ \\
\hline Durbin-Watson & 1.679 & 1.785 \\
\hline No. Observations & & $3,634,153$ \\
\hline$p^{*}<0.1, p^{* *}<0.05, p^{* * *}<0.01$ & &
\end{tabular}

performance of each restaurant daily. The results prove that the entry of Amazon Go has a negative impact on the local restaurants.

\subsection{Results of DID Model with an interaction term.}

To capture different influences on local restaurants whether the business has differentiated competitiveness, the treated variable was multiplied by interaction term indicating differentiated competitiveness measured with rating. In this data, the mean star rating was 3.7 and its $25 \%$ quantile was 3.5 . Thus, up to 3.0 stars, we can say it means the recognized quality of a restaurant is unsatisfying. From the results described in Table 3, we can know that the magnitudes of independent variables are larger than those of Table 2. It means there was not only a different magnitude of effect on local restaurants whether the business has differentiated competitiveness but also a strengthened negative effect existed. In other words, if a restaurant has relatively lower competitiveness, it declines more drastically after the entry of Amazon Go.

Overall, the results of all the models were parallel with the hypothesis of this study, there was a negative impact of Amazon Go's entry on local restaurants. Specifically, there was a large size of negative effect on local restaurants if the business had lower differentiated competitiveness.

This experiment shows when a highly technically innovative competitor comes to the market and redefines a certain kind of industry, it disrupts the nearby businesses in the same industry. In such a situation, the participants who have existed in the market but don't have enough competitiveness are ruined far more. 
Table 3. Model Results of Amazon Go in NY with a relatively lower competitiveness interaction.

\begin{tabular}{lll} 
Model: & $\mathbf{3}$ & $\mathbf{4}$ \\
\hline $\begin{array}{l}\text { Dependent variables } \\
\text { (Scale) }\end{array}$ & $\begin{array}{l}\text { Mean ratings } \\
(1 \sim 5)\end{array}$ & $\begin{array}{l}\text { Polarity Score } \\
(-1 \sim 1)\end{array}$ \\
(Intercept) & $3.5457^{* * *}$ & $0.5463^{* * *}$ \\
Independent variables & & \\
After Amazon Go * Adjacent * up to 3star rating & $\mathbf{- 0 . 7 4 5 4 * * *}$ & $\mathbf{- 0 . 1 9 1 3 * * *}$ \\
Control variable & & \\
After NY branch 1 (Brookfield) & & $-0.0167^{* * *}$ \\
After NY branch 1 (300ParkAve) & $-0.0370^{* * *}$ & -0.0022 \\
After NY branch 1 (Lexington) & -0.0033 & $0.0100^{* * *}$ \\
Relative Competitiveness & $0.0213^{* * *}$ & $0.1331^{* * *}$ \\
Counts of open at overnight time & $0.5475^{* * *}$ & $-0.0157^{* * *}$ \\
Owner claimed the business & $-0.0433^{* * *}$ & $0.0929^{* * *}$ \\
Enabled messaging service & $0.1857^{* * *}$ & $0.0131^{* * *}$
\end{tabular}

Year $2004 \sim 2021$ (without Year 2019 for multicollinearity)

\begin{tabular}{lll}
\hline Adjusted $R^{2}$ & 0.031 & 0.017 \\
\hline F-statistic & $4599.0^{* * *}$ & $2538.0^{* * *}$ \\
\hline Durbin-Watson & 1.679 & 1.785 \\
\hline No. Observations & & $3,634,153$ \\
\hline$p^{*}<0.1, p^{* *}<0.05, p^{* * *}<0.01$ & &
\end{tabular}

Table 4. Coefficients of interaction terms made by category dummies (takeout, fine dining)

\begin{tabular}{lllll} 
Model: & $\mathbf{5}$ & $\mathbf{6}$ & $\mathbf{7}$ & $\mathbf{8}$ \\
\hline $\begin{array}{l}\text { Dependent variables } \\
\text { (Scale) }\end{array}$ & Mean ratings & Polarity Score & Mean ratings & Polarity Score \\
& $(1 \sim 5)$ & $(-1 \sim 1)$ & $(1 \sim 5)$ & $(-1 \sim 1)$ \\
(Intercept) & $3.5457^{* * *}$ & $0.5463^{* * *}$ & $3.5458^{* * *}$ & $0.5463^{* * *}$
\end{tabular}

Independent variables

After Amazon Go * Adjacent $\quad-\mathbf{0 . 5 2 3 3} * * * \quad-0.1341 * * *$

* Takeout dummy

After Amazon Go * Adjacent

$-0.1682 * * * \quad-0.0399 *$

* Fine dining dummy 
Control variable

After NY branch 1 (Brookfield)

$-0.0372 * * *$

$-0.0168 * * *$

$-0.0372 * * *$

$-0.0168 * * *$

After NY branch 1

$-0.0033$

$-0.0022$

$-0.0034$

$-0.0022$

(300ParkAve)

After NY branch 1 (Lexington)

$0.0215 * * *$

$0.0100 * * *$

$0.0214 * * *$

$0.0100 * * *$

Relative Competitiveness

$0.5476 * * *$

$0.1331 * * *$

$0.5476 * * *$

$0.1331 * * *$

Counts of open at overnight

$-0.0433 * * *$

$-0.0157 * * *$

$-0.0433 * * *$

$-0.0157 * * *$

time

Owner claimed the business

$0.1857 * * *$

$0.0929 * * *$

$0.1857 * * *$

$0.0929 * * *$

Enabled messaging service

$0.0453 * * *$

$0.0131 * * *$

$0.0452 * * *$

$0.0131 * * *$

Year 2004 2021 (without Year 2019 for multicollinearity)

\begin{tabular}{lllll}
\hline Adjusted $R^{2}$ & 0.031 & 0.017 & 0.031 & 0.017 \\
\hline F-statistic & $4597.0 * * *$ & $2537.0 * * *$ & $4596.0 * * *$ & $2536.0 * * *$ \\
\hline Durbin-Watson & 1.679 & 1.785 & 1.679 & 1.785 \\
\hline No. Observations & & $3,634,153$ & \\
\hline
\end{tabular}

$p^{*}<0.1, p^{* *}<0.05, p^{* * *}<0.01$

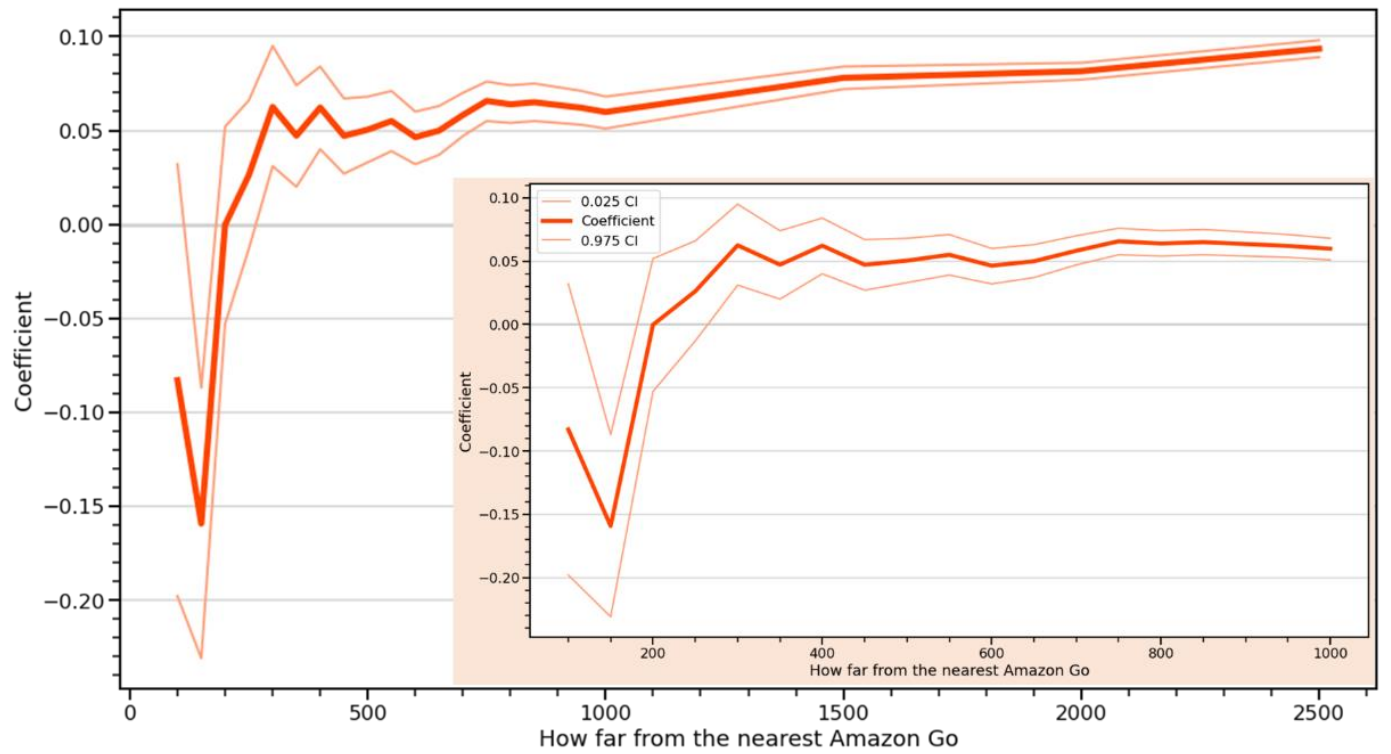

Figure 4. Coefficients and confidence intervals of Amazon Go branches in New York

Table 4 describes the change of coefficient of each interaction term made by category dummies. Based on the standard of Yelp, we added two dummy variables that mark restaurant and food each. Specifically, we labeled several category dummies, drinks, restaurants, café, takeout, convenience stores, and fine dining.
Coefficient with takeout drastically decreased than no interaction term situation. Coefficients with fine dining an interaction term made an increased record than the baseline. 


\subsection{Different heterogeneity of recognized satisfaction of restaurants after the entry of Amazon Go.}

Closer to Amazon Go, we can expect more people may have experience of using Amazon Go. Figure 4 is a graph that shows coefficients and confidence intervals of the treated group of the Amazon Go in New York controlled with Relative Competitiveness. Near the Amazon Go, the treated restaurants' heterogeneity of performance increases.

\section{Conclusion}

\subsection{Discussion}

We find there is a negative impact on the local restaurant industry by the entry of Amazon Go. It means a traditional market is weakened when a new competitor with innovative technology comes to the market. It is shown by the negative coefficients of all the treated groups in this empirical study. The results are robust because all the branches in New York report negative effects that are increasing as the treated distance gets closer. Besides, all the models based on the Brookfield branch with three dependent variables representing the performance of restaurants show the negative impact of Amazon Go. In addition, we investigate what determines the degree of negative impact by Amazon Go. Restaurants having relatively lower star ratings (up to 3 stars) get a more drastically negative influence by the entry of Amazon Go. What is more interesting is recognized satisfaction, star rating, is not the single variable that determines the substitution. We labeled the restaurants into several categories. According to the model results with interaction terms made by category variables, the coefficient with takeout drastically decreased. However, that of fine dining increased than no interaction term situation. It means Amazon Go replaces the takeout store, which usually makes snack food or fast food. However, Amazon Go shows limited substitution for the fine dining category. Therefore, we can say consumers go to Amazon Go instead of the other restaurant that mainly focuses on convenience. However, they do not select Amazon Go as the alternative of their leisure time, fine dining.

The other finding is that the standard of consumers is changed by the new competitor with innovative technology. As previous literature said [2], people seem to feel traditional experiences are burdensome after they experience new conveniences by technology. Near the Brookfield branch, the treated restaurants' heterogeneity of performance increases. We can interpret this as the following: trend created by the changed standard of customers due to the experience from Amazon Go.

\subsection{Limitations and further research plans}

To prove the second hypothesis, we could not directly track the people who have experience of using Amazon Go. Therefore, we assumed that as the distance between the restaurant and Amazon Go gets closer, people may have more potential to visit Amazon Go. The different heterogeneity of coefficients by distance can be drawn by a rare number of observations, not the change of consumers' standard by Amazon Go. It must be investigated that the results are still robust in other branches in other cities with the report of enough observations.

In the aspect of the results from the econometric model itself, the power of the model (adjusted $R^{2}$ ) was not that large. Therefore, the creation of more control variables must be done in further research.

\subsection{Contributions}

We summarize the meaning of this research as follows.

First, this research contributes to the understanding of consumer behavior when they experience a technical surprise. With this consumer comprehension, business owners or operators can get some useful implications for their further strategies.

Furthermore, we approached the research goal with a large size of data from the open forum on the website. It is valuable work that can guide other researchers who seek practical and abundant data to study business questions. In addition, from review data, we calculated the volume and polarity of word of mouth (WOM). This approach adds one more empirical case for analyzing the experience goods by text data.

The econometric model that we suggested is delicate. We showed the possibility of a DID model to understand the situation with two treatments, time and distance. The aggregated model used in this paper includes several different branches that have different treated times and distances. This approach gives other researchers the example of dealing with multi-shock scenarios.

Finally, for practical implications, the results can be useful to policymakers who need to minimize the negative impact of technology innovation and consider the harmony of current and new participants.

\section{Acknowledgments}

Sincerely acknowledge Hyejin Mun \&Younghun Kim 


\section{Appendix: List of Variables}

\begin{tabular}{|c|c|}
\hline Variables & Description \\
\hline Mean of Rating it $_{1}$ & The daily mean of star rating from reviews for each restaurant. \\
\hline Mean of Polarity Score it & The daily mean sentiment score of text from reviews for each restaurant. \\
\hline After t $_{t}$ & One if the date $t$ is after the open of the nearest Amazon Go branch, zero before. \\
\hline Adjacent $_{i}$ & $\begin{array}{c}\text { One if the restaurant } i \text { is within a certain radius of the nearest Amazon Go branch, } \\
\text { or zero outside. }\end{array}$ \\
\hline Higher $_{i}$ & $\begin{array}{c}\text { One if the restaurant } i \text { has a higher star rating than the nearest Amazon Go branch } \\
\text { or zero in the other case. }\end{array}$ \\
\hline Overnight $_{i}$ & Counts of the number of open times in overnight during a week for a restaurant $i$. \\
\hline Claimed $_{i}$ & Whether a business has been claimed by a business owner on the Yelp page. \\
\hline Messaging $_{i}$ & 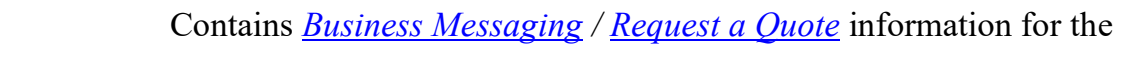 \\
\hline & $\begin{array}{c}\text { business } i \text { in their Yelp web page. This field only appears in the response for } \\
\text { businesses that have messaging enabled. }\end{array}$ \\
\hline
\end{tabular}

\section{References}

[1] Rimma Kats, "More than 100 million Americans will use proximity mobile payments in 2021", eMarketer, 2021. Accessed May 23, 2021, https://www.emarketer.com/content/more-than-100million-americans-will-use-proximity-mobilepayments-2021.

[2] Rebecca Brooks, "AMAZON GO: A BOLD, INEVITABLE RETAIL REVOLUTION", Chief Marketer, 2016. Accessed May 23, 2021, https://www.chiefmarketer.com/amazon-go-a-boldinevitable-retail-revolution/

[3] Brian Roemmele, "Will no-checkout stores like Amazon Go be commonplace by 2025?", Forbes, 2017. Accessed May 23, 2021, https://www.forbes.com/sites/quora/2017/02/10/willno -checkout-stores-like-amazon-go-becommonplace-by-2025/

[4] Blake Ives, Kathy Cossick and Dennis Adams, "Amazon Go: Disrupting retail?", Journal of Information Technology, 2019, Vol. 9(1), pp 2-12.

[5] Shorr, "ARE WE READY FOR AMAZON GO?", shorr, 2018. Accessed May 23, 2021, https://www.shorr.com/packaging-news/2018-02/arewe-ready-amazon-go

[6] Felix Richter, "What Consumers Think About Amazon Go", statista, 2018. Accessed May 23, 2021, https://www.statista.com/chart/7198/consumeropinion-on-amazon-go/

[7] Adyen, "Retail Reimagined: Experience - Not Price Is the Battleground of the Future", eMarketer, 2018. Accessed May 23, 2021, https://www.emarketer.com/content/cash-may-nolonger-be-king-for-retailers

[8] Statista Research Department, "Number of cashless transactions in Europe 2005-2020", statista, 2013. Accessed May 23, 2021,

[9] Jianxun Lian, Fuzheng Zhang, Xing Xie, and Guangzhong Sun, "Restaurant Survival Analysis with Heterogeneous Information", Proceedings of the 26th International Conference on World Wide Web Companion, 2017.

[10] H.G.Parsa, John Self,Sandra Sydnor-Busso,Hae Jin Yoon (2011). "Why Restaurants Fail? Part II - The Impact of Affiliation, Location, and Size on Restaurant Failures: Results from a Survival Analysis," Journal of Foodservice Business Research, Vo.14-4, pp 360-379.

[11] Luca Michael, "Reviews, Reputation, and Revenue: The Case of Yelp.Com", Harvard Business School NOM Unit Working Paper No. 12-016, 2016.

[12] Yelp (2021). "An Introduction to Yelp Metrics as of March 31, 2021," yelp Newsroom, Accessed June 14, 2021,

[13] Glaeser, Edward L., Hyunjin Kim, and Michael Luca, "Nowcasting the Local Economy: Using Yelp Data to Measure Economic Activity.", National Bureau of Economic Research Working Paper 24010, 2017.

[14] JooYoung Choi, Lee, C., and Ceran Y., " Smart Retail, Replaces All? Some? Different Influence of Amazon Go to Local Restaurant Industry.", Proceedings of 2021 spring Conference of The Korea Society of Management Information Systems, 2021. 